\title{
Caracterização físico-química de alho 'BRS Hozan' e 'Roxo Pérola de Caçador' em função do tempo de armazenamento
}

\section{Physico-chemical characterization of 'BRS Hozan' and 'Roxo Pérola de Caçador' garlic as a function of storage time}

ANTONIA TAMIRES MONTEIRO BESSA ${ }^{1}$

WELDER DE ARAÚJO RANGEL LOPES ${ }^{1,2}$

OTACIANA MARIA DOS PRAZERES DA SILVA'

MAYKY FRANCLEY PEREIRA DE LIMA' ${ }^{1}$

PEDRO RAMON HOLANDA DE OLIVEIRA' ${ }^{1}$

HIAGO COSTA DE SOUSA ${ }^{1}$

ADRIANO FONTES AGUIAR ${ }^{1}$

MARIA ZULEIDE DE NEGREIROS'

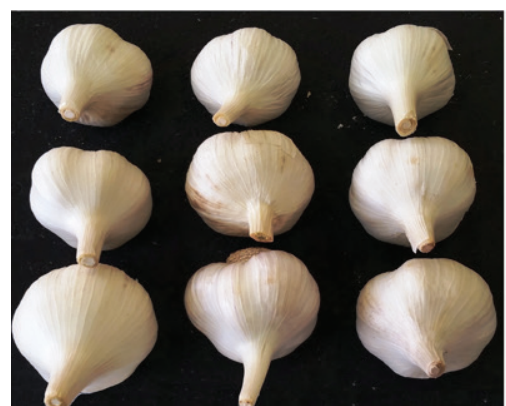

cv. BRS Hozan

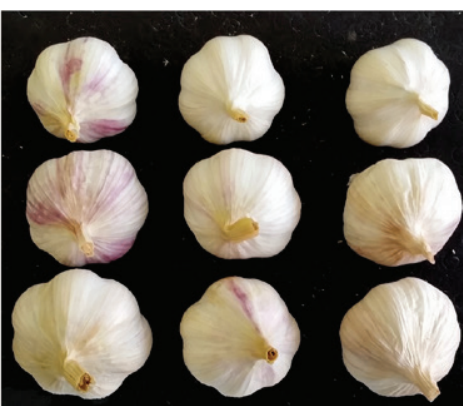

cv. Roxo Pérola de Caçador

\section{Cultivares de alho produzido em Portalegre, RN, Brasil.}

Fotos: W.A.R. Lopes

\section{RESUMO}

Ormazenamento pós-colheita pode ser um instrumento útil para que os produtores de alho proporcionem produtos de boa qualidade, com preços acessíveis para os consumidores, não apenas no momento da colheita. Assim, o objetivo deste estudo foi caracterizar as mudanças nas propriedades físico-químicas do alho comum e nobre, durante o tempo de armazenamento, em condições ambientais. Os tratamentos foram dispostos em parcelas subdivididas. As parcelas foram representadas pelas cultivares de alho: BRS Hozan e Roxo Pérola de Caçador e as subparcelas foram representadas pelo tempo de armazenamento: 0, 30, 60, 90 e 120 dias. O delineamento experimental utilizado foi o de blocos casualizados, com quatro repetições. Foram avaliadas: perda de peso, índice de chochamento, sólidos solúveis, acidez titulável, pH, relação sólidos solúveis/acidez titulável, pungência, sólidos totais e índice industrial. Com o tempo de armazenamento, houve aumento na perda de peso, índice de chochamento e acidez titulável, além de redução no pH, relação SS/AT e índice industrial, para as duas cultivares avaliadas. $\bigcirc$ alho manteve o padrão ideal para consumo até os 120 dias de armazenamento, para ambas as cultivares. A cultivar Roxo Pérola de Caçador teve potencial de armazenamento superior a cultivar BRS Hozan.

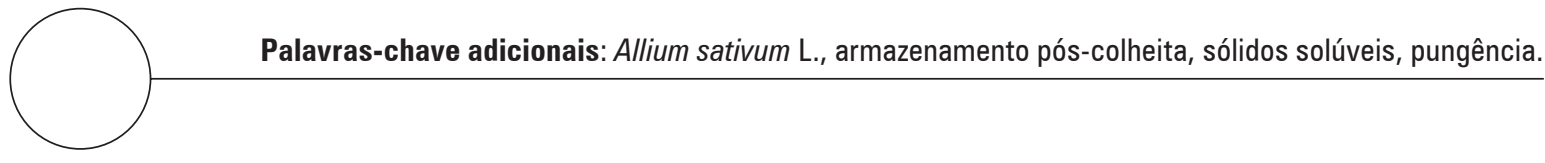

1 Centro de Ciências Agrárias, Universidade Federal Rural do Semi-Árido (UFERSA), Mossoró-RN (Brasil).

ORCID Bessa, A.T.M.: 0000-0002-8068-9068; ORCID Lopes, W.d.A.R.: 0000-0002-9380-6710; ORCID Silva, O.M.d. P.: 0000-0002-0634-5419; ORCID Lima, M.F.P.: 0000-0002-4405-7354; ORCID Oliveira, P.R.H.: 0000-0001-5807-9610; Sousa, H.C.: 0000-0003-3109-6407; Aguiar, A.F.: 0000-0001-7393-6094; Negreiros, M.Z.: 0000-0002-0665-326X

2 Autor para correspondência.welder.lopes@hotmail.com 


\section{ABSTRACT}

Post-harvest storage can be a useful instrument for garlic producers to provide good quality produce with affordable prices for consumers. Thus, the objective of this study was to evaluate the changes in the physicochemical characteristics of common and noble garlic during storage under environmental conditions. The treatments were distributed in split plots; the plots were defined by the garlic cultivars: 'BRS Hozan' and 'Roxo Pérola de Caçador', and the storage times: 0, 30, 60, 90 and 120 days. A randomized block design was used, with four replications. We evaluated the weight loss, pith index, soluble solids, titratable acidity, $\mathrm{pH}$, soluble solids/ titratable acidity, pungency, total solids and industrial index. For storage time, there was an increase in the weight loss, chopping index and titratable acidity, as well as a reduction in the $\mathrm{pH}, \mathrm{SS} / \mathrm{TA}$ ratio and industrial index for the two evaluated cultivars. The garlic maintained the ideal pattern for consumption for up to 120 days of storage for both cultivars. The cultivar Roxo Pérola de Caçador had a storage potential that was superior to that of the cultivar BRS Hozan.

Additional key words: Allium sativum L., postharvest storage, soluble solids, pungency.

Data de recepção: 16-01-2017 Aprovado para publicação: 30-09-2017

$(2$

$\int \longdiv { \text { INTRODUÇÃO } }$

Um dos principais problemas encontrados pelos produtores brasileiros de alho ainda é a concorrência com o alho importado, principalmente da China, que apresenta boa qualidade em termos de aparência dos bulbos, mas inferior ao nacional quanto aos aspectos condimentares, além de preços altamente competitivos no mercado (ANAPA, 2014). Na China, a produção de alho é subsidiada pelo governo e, ao entrar no Brasil, o custo final do produto é menor, garantindo mercado (Prati et al., 2010).

Considerado como um dos principais condimentos utilizados na culinária brasileira e em outros países, o alho se destaca por possuir características excepcionais de sabor e aroma. Os compostos organosulfurados são responsáveis pela pungência, sabor e aroma característico dessa hortaliça (Botrel e Oliveira, 2012).

As análises físico-químicas do alho podem indicar se o produto é mais apropriado ao consumo in natura ou para a indústria, maior capacidade de armazenamento pós-colheita (Chitarra e Chitarra, 2005) e também, a melhor época para a realização da colheita (Oliveira et al., 2004). Variáveis como pH, acidez titulável, sólidos solúveis, relação sólidos solúveis/acidez titulável, açúcares solúveis totais, sólidos totais, pungência, índice industrial, dentre outros, são importantes para a determinação da qualidade do alho (Soares, 2013; Lopes et al., 2016a; Lucena et al., 2016a).
$\mathrm{O}$ pH é um indicativo de sabor de uma hortaliça, tendo relação inversa à acidez. Contudo, a capacidadetampão de alguns sucos permite que ocorram grandes variações na acidez titulável, sem variações apreciáveis no $\mathrm{pH}$, que pode ser observado na cultura do alho (Chitarra e Chitarra, 2005). Enquanto a acidez é atribuída principalmente aos ácidos orgânicos, que contribuem para o aroma característico, por apresentar componentes voláteis, além de compostos fenólicos, que apresentam caráter acídico, podendo contribuir para a acidez e adstringência. De acordo com vários estudos, quanto mais elevada for à acidez, melhor será a característica industrial do alho (Lopes et al., 2016a; Lucena et al., 2016b).

A determinação do teor de sólidos solúveis também é de grande importância, pois nesta fração encontramse os açúcares responsáveis em parte pelo sabor característico do alho (Lopes et al., 2016a; Lucena et al., 2016b). Os açúcares presentes nas espécies do gênero Allium, incluindo o alho, são glicose $(1,0 \%)$, frutose $(1,5 \%)$ e sacarose $(1,0-1,5 \%)$, juntamente com uma série de oligossacarídeos (Souza e Macêdo, 2009).

O valor de sólidos totais do alho em comparação com outras hortaliças (cebola, cenoura, pimentão, tomate) é bastante acentuado, apresentando as melhores perspectivas para a desidratação, devido ao maior rendimento comparativo, ou seja, obtém-se maior 
quantidade de alho desidratado por peso de matéria prima utilizada (Souza e Macêdo, 2009).

O rendimento industrial do alho, ou seja, a quantidade de produto desidratado produzido em relação à quantidade de matéria-prima recebida na indústria depende em grande parte do conteúdo de sólidos totais presentes na matéria prima. Assim, cultivares com elevado nível de sólidos totais proporcionam maior rendimento industrial (Lopes et al., 2016a; Lucena et al., 2016b), reduzindo sensivelmente os custos de produção, pois menor quantidade de água deverá ser removida do produto (Souza e Macêdo, 2009).

A determinação do teor de ácido pirúvico nos extratos de alho é um dos meios mais simples para aferir a intensidade da pungência. Esta é um fator essencial na escolha da matéria-prima, pois quanto maior, mais pungentes são o sabor e aroma do produto acabado, o que é desejado pelos consumidores (Vargas et al., 2010; Lopes et al., 2016a; Lucena et al., 2016a).

O armazenamento em condição ambiente é muito utilizado para as culturas da cebola e do alho, permitindo aos produtores a comercialização escalonada do produto, obtendo-se melhores preços e evitando a concentração de ofertas em período curto do ano (Oliveira et al., 2004). Porém, é necessária a realização de trabalhos visando a determinar o melhor tempo de armazenamento na composição físico-química e, consequentemente, na qualidade dos bulbos.

Desse modo, o objetivo deste estudo foi caracterizar as mudanças nas propriedades físico-químicas do alho comum e nobre, ao longo do tempo de armazenamento, em condições ambientais.

\section{MATERIAIS E MÉTODOS}

Os bulbos de alho comum e nobre foram provenientes de um plantio realizado em 2015 no município de Portalegre, Rio Grande do Norte, Brasil. A área localiza-se 6³'17" S e 38 0'17" W e altitude de aproximadamente $630 \mathrm{~m}$. O fotoperíodo da região possui pouca variação, em torno de $12 \mathrm{~h}$, durante todo o ano. A região possui clima tropical chuvoso, do tipo Aw, de acordo com a classificação de Köppen-Geiger, com temperatura média anual em torno dos $23^{\circ} \mathrm{C}$ e índice pluviométrico de aproximadamente $1.100 \mathrm{~mm}$ por ano, concentrados entre os meses de fevereiro a maio.
O delineamento experimental utilizado foi o de blocos casualizados, com quatro repetições. Os tratamentos foram dispostos em parcelas subdivididas, sendo as parcelas representadas pelas cultivares de alho: BRS Hozan e Roxo Pérola de Caçador, e as subparcelas, pelo tempo de armazenamento: 0, 30, 60, 90 e 120 d após o toalete. Cada repetição continha 15 bulbos correspondentes aos tempos de armazenamento, totalizando 75 bulbos em cada parcela experimental.

A BRS Hozan é uma cultivar de alho comum, que possui bulbos com formato irregular e não necessita de vernalização para produzir bulbos em regiões tropicais (Honorato et al., 2013; Lucena et al., 2016a; 2016b). A Roxo Pérola de Caçador pertence ao grupo dos alhos nobres, de ciclo tardio, e possui bulbos redondos e grandes (Resende et al., 2013). Além disso, é considerada precoce entre as cultivares nobres, menos exigente em fotoperíodo e temperatura, e por isso está entre as mais indicadas para a região nordeste do Brasil, com uso da vernalização (Lopes et al., 2016a; 2016b). Assim, os bulbos-semente da cultivar Roxo Pérola de Caçador passaram pelo processo de vernalização por um período de $50 \mathrm{~d}$ em câmara frigorífica à temperatura de $4^{\circ} \mathrm{C} \pm 1^{\circ} \mathrm{C}$ e umidade relativa de $70 \%$, antes do plantio dos bulbilhos no campo.

O plantio das cultivares de alho foi realizado a uma profundidade de $0,05 \mathrm{~m}$ em canteiros de $0,20 \mathrm{~m}$ de altura, 1,00 m de largura, com cinco fileiras simples no espaçamento de $0,20 \times 0,10 \mathrm{~m}$. Baseada na análise de solo, foi realizada a adubação de plantio com 30 $\mathrm{kg}$ ha-1 de $\mathrm{N}$ (sulfato de amônio), $120 \mathrm{~kg} \mathrm{ha}^{-1}$ de $\mathrm{P}_{2} \mathrm{O}_{5}$ (superfosfato simples), $60 \mathrm{~kg} \mathrm{ha}^{-1} \mathrm{de}_{2} \mathrm{O}$ (cloreto de potássio), $9,71 \mathrm{~kg} \mathrm{ha}^{-1}$ de B (ácido bórico) e $60 \mathrm{~kg} \mathrm{ha}^{-1}$ de Zn (sulfato de zinco) e $50 \mathrm{~kg} \mathrm{ha}^{-1}$ de Pole Fértil ${ }^{\circledR}$, Integral Agroindustrial, Brasil, à base de esterco bovino e de galinha decompostos, com $1 \%$ de $\mathrm{N}$ total, $15 \%$ de Composto orgânico, 50\% de umidade, pH 6,0 e CTC de $80 \mathrm{mmol}_{\mathrm{c}} \mathrm{dm}^{-3}$. As aplicações de $\mathrm{N}$ em cobertura foram realizadas aos 20, 35 e $50 \mathrm{~d}$ após o plantio, utilizando como fonte a ureia.

Utilizou-se a irrigação por microaspersão, com vazão de $40 \mathrm{~L} \mathrm{~h} \mathrm{~h}^{-1}$. Visando à prevenção e controle de doenças como mancha púrpura (Alternaria porri (Ellis) Cif.) e ferrugem (Puccinia allii Castagne), realizouse pulverizações com produtos à base de mancozeb (Manzate ${ }^{\circledR}$, DuPont do Brasil S.A., 2,5 g do princípio ativo/L da solução), em intervalos de $7 \mathrm{~d}$. O controle de pragas, como tripes e ácaros, foi efetuado mediante pulverizações em intervalos de $15 \mathrm{~d}$ com produtos 
à base de deltametrina (Decis ${ }^{\circledR}$, Bayer CropScience Ltda, Brasil, 0,3 $\mathrm{mL}$ do princípio ativo/L da solução) e/ou clorfenapir (Pirate ${ }^{\circledR}$, BASF S.A., Brasil, $0,5 \mathrm{~mL}$ do princípio ativo/L da solução). O manejo de plantas daninhas foi realizado por meio de capinas manuais, efetuadas sempre que necessário, de modo que a cultura permanecesse sem interferência.

Suspendeu-se a irrigação $3 \mathrm{~d}$ antes da colheita, quando as plantas apresentaram sinais de maturação, caracterizadas pelo amarelecimento e secamento parcial da parte aérea e/ou tombamento das plantas. As plantas colhidas foram submetidas ao processo de "pré-cura", permanecendo por $3 \mathrm{~d}$ expostas ao sol, de forma que as folhas de uma planta cobrissem os bulbos de outra, protegendo-os da radiação solar direta. Em seguida, realizou-se a cura de armazém, onde as plantas permaneceram por um período de $17 \mathrm{~d}$ em local sombreado, seco e arejado. Após o processo de cura, realizou-se toalete, que consiste na limpeza dos bulbos, descartando-se as raízes, folhas e túnicas secas e sujas. Após o toalete, os bulbos de alho foram colocados em bandejas distribuídas em prateleiras, conforme o tempo de armazenamento $(0,30,60,90$, 120 d), em uma sala do Centro de Ciências Agrárias da Universidade Federal Rural do Semi-Árido (UFER$\mathrm{SA}$ ), Mossoró, RN, Brasil, em temperatura ambiente (média diária de $28^{\circ} \mathrm{C}$ ), luz natural, seca e arejada.

Em cada tempo de armazenamento, os bulbos foram encaminhados para o Laboratório de Pós-colheita do Centro de Pesquisas Vegetais do Semiárido Nordestino - CPVSA/ UFERSA, Mossoró, RN, Brasil, para a realização das análises:

1) Perda de peso (\%) obtida pela diferença entre a massa inicial dos bulbos após o toalete e a massa dos bulbos em cada tempo de armazenamento;

2) $O$ índice de chochamento (\%) determinado pela relação entre número de bulbilhos chochos e número total de bulbilhos;

3) Acidez titulável (AT), utilizou-se $1 \mathrm{~g}$ de pasta de alho, diluída em água destilada até o volume de 50 $\mathrm{mL}$. Adicionaram-se duas gotas de fenolftaleína alcoólica a 1\%. Realizou-se a titulação com solução de $\mathrm{NaOH} 0,1 \mathrm{~N}$, até o ponto de viragem caracterizada pela cor rósea. Os resultados foram expressos em $\mathrm{mEq} \mathrm{H}_{3} \mathrm{O}^{+} / 100 \mathrm{~g}$;

4) Potencial hidrogeniônico $(\mathrm{pH})$, determinado com auxílio de potenciômetro com ajuste automático de temperatura, devidamente padronizado com soluções tampão $\mathrm{pH}=7,0$ e $\mathrm{pH}=4,0$;

5) Sólidos solúveis (SS), expressos em percentagem, foram quantificados diretamente do suco de alho homogeneizado, filtrado em tecido fait, $100 \%$ poliéster, por meio de leitura em refratômetro digital (modelo PR-100, Palette@, Atago Co, LTD. Japan) com compensação automática de temperatura;

6) Relação sólidos solúveis/acidez titulável (SS/AT) obtida pela relação entre o teor de sólidos solúveis e a acidez titulável;

7) Pungência, estimada por meio da determinação do ácido pirúvico, utilizando-se o reagente 2,4-Dinitrofenilhidrazina (DNPH). Em erlenmeyer, adicionou-se $0,2 \mathrm{~mL}$ do suco do alho, 1,5 $\mathrm{mL}$ de ácido tricloroacético a $5 \%$ e $18,3 \mathrm{~mL}$ de água destilada, para obtenção do extrato. Agitou-se o material. Em tubo de ensaio, adicionou-se $1 \mathrm{~mL}$ do extrato, $1 \mathrm{~mL}$ da solução de 2,4-dinitrofenilhidrazina $(\mathrm{DNPH})$ e $1 \mathrm{~mL}$ de água destilada. $\mathrm{O}$ material foi agitado em vórtex. Posteriormente, os tubos de ensaio foram levados ao banho-maria a $37^{\circ} \mathrm{C}$ durante 10 minutos. Resfriou-se o material em banho de gelo e adicionou-se $5 \mathrm{~mL}$ de $\mathrm{NaOH} 0,6 \mathrm{~N}$, por tubo de ensaio. Agitou-se em vórtex, e manteve-se em repouso por cinco minutos para desenvolver a cor amarela. As absorbâncias foram lidas em espectrofotômetro a $420 \mathrm{~nm}$. O piruvato de sódio foi usado como padrão. O cálculo de pungência foi realizado por meio da elaboração da curva padrão do piruvato de sódio em sete concentrações $(0,0$; 0,$\left.2 ; 0,4 ; 0,6 ; 0,8 ; 1,0 ; 1,2 \mathrm{mmol} \mathrm{L}^{-1}\right)$. Os resultados foram obtidos em $\mu$ moles de ácido pirúvico por $\mathrm{mL}$ de suco de alho ( $\left.\mu \mathrm{mol} \mathrm{mL}^{-1}\right)$;

8) Sólidos totais (ST), foram debulhados cinco bulbos, de cada tratamento; os bulbilhos obtidos foram levados a uma estufa com circulação forçada de ar, com temperatura de $65^{\circ} \mathrm{C}$, até atingirem massa seca constante. Os ST foram calculados pela diferença entre 100 e o teor de umidade dos bulbilhos e os resultados foram expressos em $\mathrm{g}$ de sólidos totais/100 g de alho (\%);

9) Índice industrial (II), calculado pela fórmula: II = (Sólidos totais x ácido pirúvico)/ 100 (Carvalho et al., 1991).

Os dados foram submetidos às análises de variância e regressão. As médias referentes às cultivares foram 
comparadas pelo teste de $\mathrm{t}$ de Student a $5 \%$ de probabilidade, utilizando-se o software Sisvar ${ }^{\circledR}$ v. 5.3 (Ferreira, 2008) e os tempos de armazenamento foram submetidos à análise de regressão, obedecendo-se ao nível de significância de 5\% de probabilidade pelo teste $\mathrm{F}$

\section{RESULTADOS E DISCUSSÃO}

Verificou-se efeito significativo da interação entre cultivares e tempo de armazenamento para perda de peso, índice de chochamento, $\mathrm{pH}$, acidez titulável e sólidos solúveis, e efeito isolado de cultivares e tempo de armazenamento para a relação SS/AT. Para sólidos totais, houve efeito significativo apenas de cultivares, enquanto que para o índice industrial, apenas do tempo de armazenamento. Para a pungência, não se observou efeito significativo de nenhum dos fatores.

Houve aumento da perda de peso com o tempo de armazenamento, com valores máximos estimados de até $22,88 \%$ para a cultivar BRS Hozan e $8,95 \%$ para a cultivar Roxo Perola de Caçador, aos 120 d após o toalete (Fig. 1A). A redução no peso ocorre devido à perda de umidade dos bulbos e da redução na matéria seca utilizada como substrato no processo de respiração celular durante o armazenamento (Chitarra e Chitarra, 2005). Sobre isso, Carvalho et al. (1991) encontraram perda de peso de até $10,88 \%$, com 120 d de armazenamento para a cultivar Amarante. Oliveira et al. (2004) observaram maiores valores de perda de massa de 45,66, 47,02, 48,98 e 51,21\% entre as cultivares Gigante Curitibanos, Gravatá, Gigante Roxo

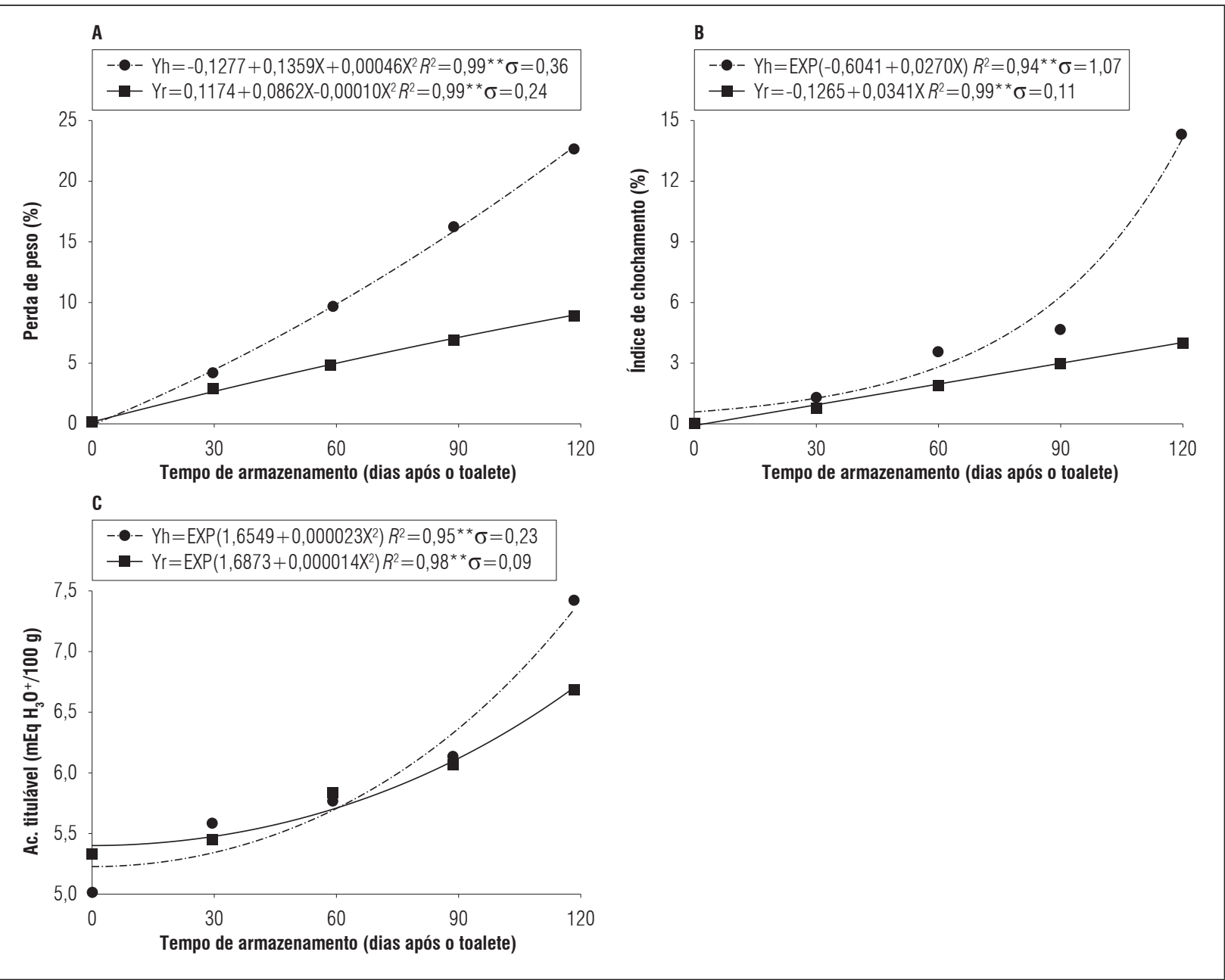

Figura 1. Perda de peso (A), índice de chochamento (B) e acidez titulável (C) de cultivares de alho armazenado, BRS Hozan (h) e Roxo Pérola de Caçador (r) [significativo ao nível de $5 \%\left({ }^{*}\right)$ e $1 \%\left({ }^{* *}\right)$ de probabilidade]. 
e Gigante Lavínia, respectivamente, em função das épocas de colheitas e potencial de armazenamento em alho.

A cultivar Roxo Pérola de Caçador apresentou menor perda de peso ao longo do tempo de armazenamento, embora significativo apenas dos $90 \mathrm{~d}$ após o toalete (Tab. 1). É possível que a cultivar BRS Hozan, após o processo de cura, apresentasse maior teor de umidade nas túnicas dos bulbos, em relação à Roxo Pérola de Caçador, resultando em maiores perdas de peso ao longo do período de armazenamento. Conforme Carvalho et al. (1991), bulbos de alho com elevado teor de água perdem maior porcentagem de peso do que aqueles com menor teor.

Para o índice de chochamento observou-se comportamento diferenciado entre as cultivares. Para a cultivar Roxo Pérola de Caçador verificou-se efeito linear crescente, com valores mínimos estimados de 0,01\%

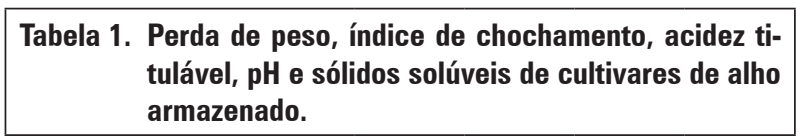

\begin{tabular}{|c|c|c|c|c|c|}
\hline \multirow[b]{2}{*}{ Cultivar } & \multicolumn{5}{|c|}{$\begin{array}{l}\text { Tempo de armazenamento } \\
\text { (dias após o toalete) }\end{array}$} \\
\hline & 0 & 30 & 60 & 90 & 120 \\
\hline \multicolumn{6}{|c|}{ Perda de peso (\%) } \\
\hline R. Pérola de Caçador & - & 2,88 a & 4,82 a & $6,89 \mathrm{~b}$ & $9,04 \mathrm{~b}$ \\
\hline BRS Hozan & - & 4,16 a & 9,56 a & $16,28 \mathrm{a}$ & $22,71 \mathrm{a}$ \\
\hline Desvio padrão & - & 1,88 & 1,88 & 1,88 & 1,88 \\
\hline \multicolumn{6}{|c|}{ Índice de chochamento (\%) } \\
\hline R. Pérola de Caçador & $0,00 \mathrm{a}$ & $0,76 \mathrm{a}$ & $1,86 \mathrm{a}$ & $2,99 \mathrm{a}$ & $4,01 \mathrm{~b}$ \\
\hline BRS Hozan & $0,00 \mathrm{a}$ & $1,28 a$ & $3,54 a$ & 4,63 a & $14,24 \mathrm{a}$ \\
\hline Desvio padrão & 0,68 & 0,68 & 0,68 & 0,68 & 0,68 \\
\hline \multicolumn{6}{|c|}{ Acidez titulável $\left(\mathrm{mEq} \mathrm{H} \mathrm{O}^{+} / 100 \mathrm{~g}\right)$} \\
\hline R. Pérola de Caçador & 5,34 a & $5,45 \mathrm{a}$ & $5,84 \mathrm{a}$ & 6,07 a & $6,68 \mathrm{~b}$ \\
\hline BRS Hozan & 5,02 a & $5,59 a$ & $5,77 a$ & $6,10 \mathrm{a}$ & $7,41 \mathrm{a}$ \\
\hline Desvio padrão & 0,18 & 0,18 & 0,18 & 0,18 & 0,18 \\
\hline \multicolumn{6}{|c|}{$\mathrm{pH}$} \\
\hline R. Pérola de Caçador & $6,01 \mathrm{~b}$ & $5,95 a$ & 5,93 a & 5,93 a & $5,92 a$ \\
\hline BRS Hozan & 6,08 a & 5,97 a & 5,96 a & $5,95 a$ & $5,88 \mathrm{~b}$ \\
\hline Desvio padrão & 0,01 & 0,01 & 0,01 & 0,01 & 0,01 \\
\hline \multicolumn{6}{|c|}{ Sólidos solúveis (\%) } \\
\hline R. Pérola de Caçador & $33,20 \mathrm{~b}$ & $33,63 \mathrm{~b}$ & $33,85 b$ & 34,06 b & $33,35 \mathrm{~b}$ \\
\hline BRS Hozan & $37,45 a$ & $38,92 \mathrm{a}$ & $39,30 \mathrm{a}$ & 39,76 a & 39,99 a \\
\hline Desvio padrão & 0,34 & 0,34 & 0,34 & 0,34 & 0,34 \\
\hline
\end{tabular}

Médias seguidas pela mesma letra, na coluna, para cada característica, não diferem entre si pelo teste t a $5 \%$ de probabilidade. aos 0 d e máximo de $3,97 \%$ aos 120 d após o toalete. Enquanto para a cultivar BRS Hozan, observou-se comportamento exponencial, com valores mínimos e máximos estimados de $0,54 \%$ aos 0 d e $14,02 \%$, respectivamente, aos $120 \mathrm{~d}$ após o toalete (Fig. 1B). Em relação às cultivares em cada tempo de armazenamento, verificou-se efeito significativo apenas para o tempo de $120 \mathrm{~d}$ após o toalete, tendo a cultivar BRS Hozan apresentado valores superiores à Roxo Pérola de Caçador (Tab. 1).

O chochamento é comum nos alhos armazenados e apresenta índice diferenciado entre clones submetidos ou não ao toalete. Oliveira et al. (2004) verificaram índice de chochamento médio de $12,76 \%$, para as cultivares Gigante de Curitibanos, Gravatá, Gigante Roxo e Gigante de Lavínia, com 180 d de armazenamento, ao passo que Soares et al. (2015), avaliando índice de chochamento de cultivares após $20 \mathrm{~d}$ de cura, encontraram valores variando de 0 até $5,60 \%$. Segundo os autores, o índice de chochamento ou a percentagem de bulbilhos chochos estão entre os defeitos mais graves apontados pelas portarias ministeriais, sendo $15 \%$ o máximo permitido como limite para que o lote seja considerado do tipo comercial.

Considerando a acidez titulável, observou-se comportamento exponencial crescente, para as duas cultivares, com o tempo de armazenamento, sendo o menor valor estimado de $5,23 \mathrm{mEq} \mathrm{H}_{3} \mathrm{O}^{+} / 100 \mathrm{~g}$ aos $0 \mathrm{~d}$, e o maior de 7,34 $\mathrm{mEq} \mathrm{H}_{3} \mathrm{O}^{+} / 100 \mathrm{~g}$ aos 120 ds após o toalete, para o BRS Hozan, ao passo que o mínimo e o máximo para a cultivar Roxo Pérola de Caçador foram de 5,41 aos $0 \mathrm{~d}$ e $6,70 \mathrm{mEq} \mathrm{H}_{3} \mathrm{O}^{+} / 100 \mathrm{~g}$, respectivamente, aos $120 \mathrm{~d}$ de armazenamento (Fig. 1C). Resultado semelhante foi encontrado por Berno (2013), o qual verificou tendência de aumento na acidez titulável durante o tempo de armazenamento.

A acidez em produtos hortícolas é atribuída, principalmente, aos ácidos orgânicos que se encontram dissolvidos nos vacúolos das células, tanto na forma livre como combinada com sais, ésteres, glicosídeos, etc (Chitarra e Chitarra, 2005). Em alguns produtos, os ácidos orgânicos não só contribuem para a acidez como também para o aroma característico, porque alguns componentes são voláteis (Chitarra e Chitarra, 2005). No presente trabalho, a acidez aumentou devido a uma maior concentração dos ácidos orgânicos com o tempo de armazenamento.

A acidez titulável pode apresentar valores diferentes entre clones de alho e regiões de cultivo. Carvalho et al. (1991) observaram valores de acidez total inferiores 
ao que foi observado no trabalho, variações de 1,08 a $1,34 \%$ aos $120 \mathrm{~d}$ de armazenamento, ao passo que Lopes et al. (2016a) verificaram acidez semelhantes ao que foi encontrado no trabalho, valores de 5,82 a 7,45 $\mathrm{mEq} \mathrm{H}_{3} \mathrm{O}^{+} / 100 \mathrm{~g}$. Lucena et al. (2016a) encontraram acidez de 4,64 a 8,44 $\mathrm{mEq} \mathrm{H}_{3} \mathrm{O}^{+} / 100 \mathrm{~g}$ para a cultivar BRS Hozan quando cultivada em Baraúna-RN, Brasil, e 5,82 a 6,54 $\mathrm{mEq} \mathrm{H}_{3} \mathrm{O}^{+} / 100 \mathrm{~g}$ quando cultivada em Governador Dix-sept Rosado-RN, Brasil. Soares (2013), estudando as cultivares Amarante, Branco Mossoró, Cateto Roxo, Catiguá, Caturra, Centenário, Chileno PR, Chinês Real, Gravatá, Mexicano e Morano Arequipeno, nas condições de Governador Dix-sept Rosado-RN, obteve acidez titulável variando entre 5,33 e 7,76 $\mathrm{mEq} \mathrm{H}_{3} \mathrm{O}^{+} / 100 \mathrm{~g}$.

Analisando as cultivares nos diferentes tempos de armazenamento, verificou-se que houve efeito apenas para 120 d de armazenamento, tendo a cultivar BRS Hozan acidez titulável superior à Roxo Pérola de Caçador (Tab. 1).

Com relação ao pH obteve-se variação de 6,07 aos $0 \mathrm{~d}$ a 5,88 aos 120 d após o toalete para a cultivar BRS Hozan, ao passo que a Roxo Pérola de Caçador variou de 6,01 aos $0 \mathrm{~d}$ a 5,92 aos $120 \mathrm{~d}$ após o toalete (Fig. 2A). Os resultados obtidos são próximos aos encontrados por Lopes et al. (2016a) que verificaram variação de 5,76 a 6,04 na região de Baraúna-RN, Brasil. Para as cultivares, em cada período de armazenamento, houve efeito significativo apenas para os tempos de $0 \mathrm{e}$ $120 \mathrm{~d}$; para os demais períodos, os valores foram estatisticamente semelhantes (Tab. 1).

Para o teor de sólidos solúveis (SS) verificou-se comportamento quadrático com o tempo de armazenamento,

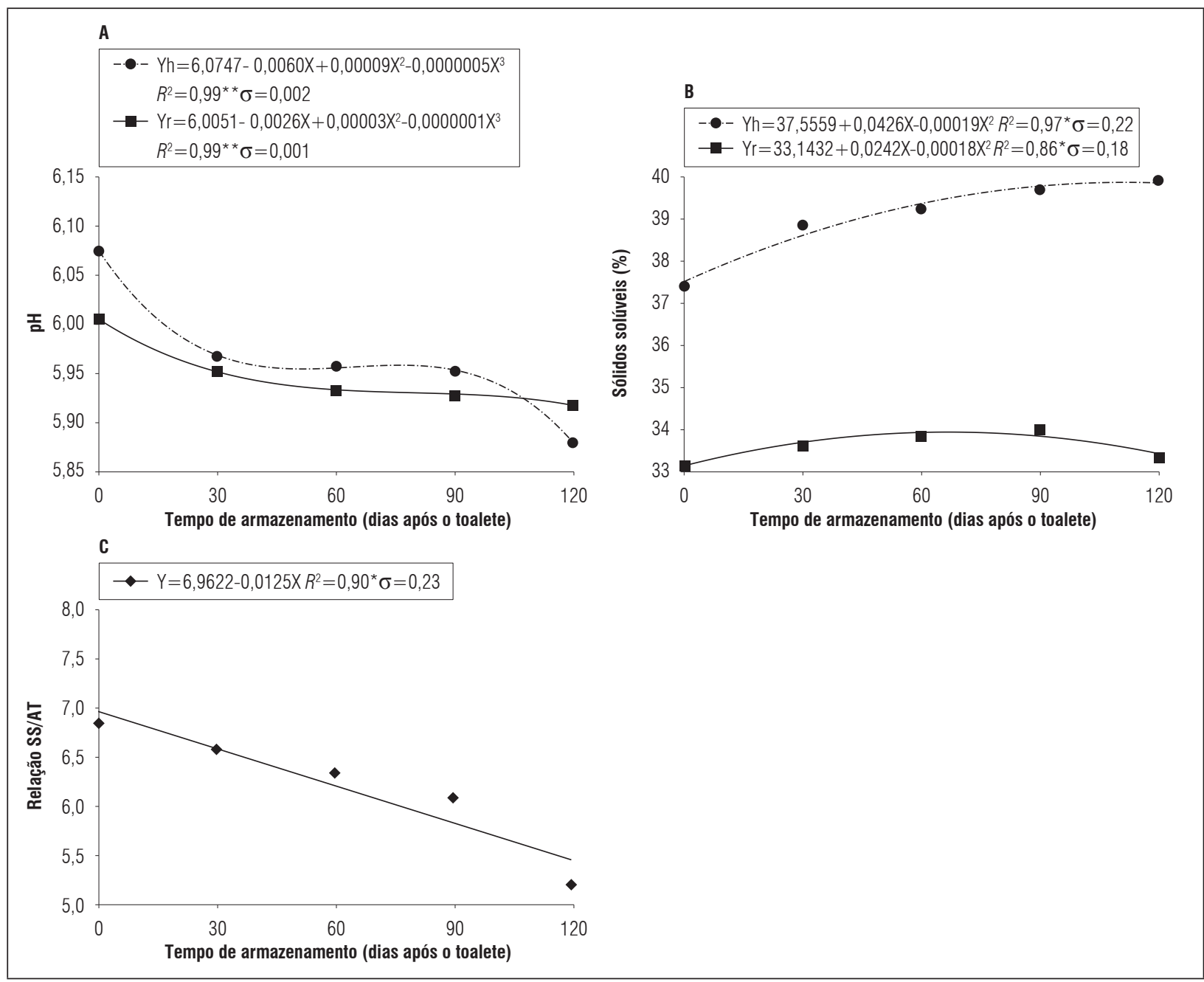

Figura 2. pH (A), sólidos solúveis (B) e relação SS/AT (C) de cultivares de alho armazenado, BRS Hozan (h) e Roxo Pérola de Caçador (r) [significativo ao nível de $5 \%\left({ }^{*}\right)$ e $1 \%\left({ }^{* *}\right)$ de probabilidade]. 
atingindo valores máximos estimados de 39,94\% para a cultivar BRS Hozan, aos $111 \mathrm{~d}$ de armazenamento, e 33,95\% para a Roxo Pérola de Caçador aos 66 d após o toalete (Fig. 2B). Houve efeito significativo para as cultivares, em todos os períodos de armazenamento, destacando-se a BRS Hozan, com valores superiores à Roxo Pérola de Caçador (Tab. 1). Resende et al. (2003) observaram pequena variação nas cultivares avaliadas entre 35,75 a $37,25 \%$, sem diferenças significativas entre si. Ao passo que Lopes et al. (2016a) encontraram valor médio de $33,91 \%$ para a Roxo Pérola de Caçador e Lucena et al. (2016a) observaram valores máximos para a cultivar BRS Hozan de $38,20 \%$ no município de Baraúna-RN e 38,40\% em Governador Dix-sept Rosado-RN.

Os sólidos solúveis representam a concentração de substâncias dissolvidas no conteúdo celular, entre as quais se destacam as vitaminas, pectinas, fenóis, ácidos orgânicos, pigmentos e, principalmente, os açúcares (Beckles, 2012). A diferença dos sólidos solúveis, nas cultivares, em função dos períodos de armazenamento pode estar relacionada às próprias características das cultivares, bem como ao grau de maturação dos bulbos utilizados na análise, pois neste caso, com o amadurecimento, o amido é hidrolisado e os açúcares complexos vão se transformando em açúcares simples (Chitarra e Chitarra, 2005).

Para a relação SS/AT observou-se comportamento linear decrescente com o aumento do tempo de armazenamento, com variação média de 6,96 aos $0 \mathrm{~d}$ e 5,45 aos 120 d após o toalete (Fig. 2C), em virtude de o aumento na acidez, em função do tempo de armazenamento, ser maior do que o observado para sólidos solúveis.

Analisando as cultivares, verifica-se que a BRS Hozan proporcionou relação SS/AT superior à Roxo Pérola de Caçador (Tab. 2). A relação SS/AT é uma das melhores formas de avaliação do sabor de frutas e hortaliças, sendo mais representativa do que a medição

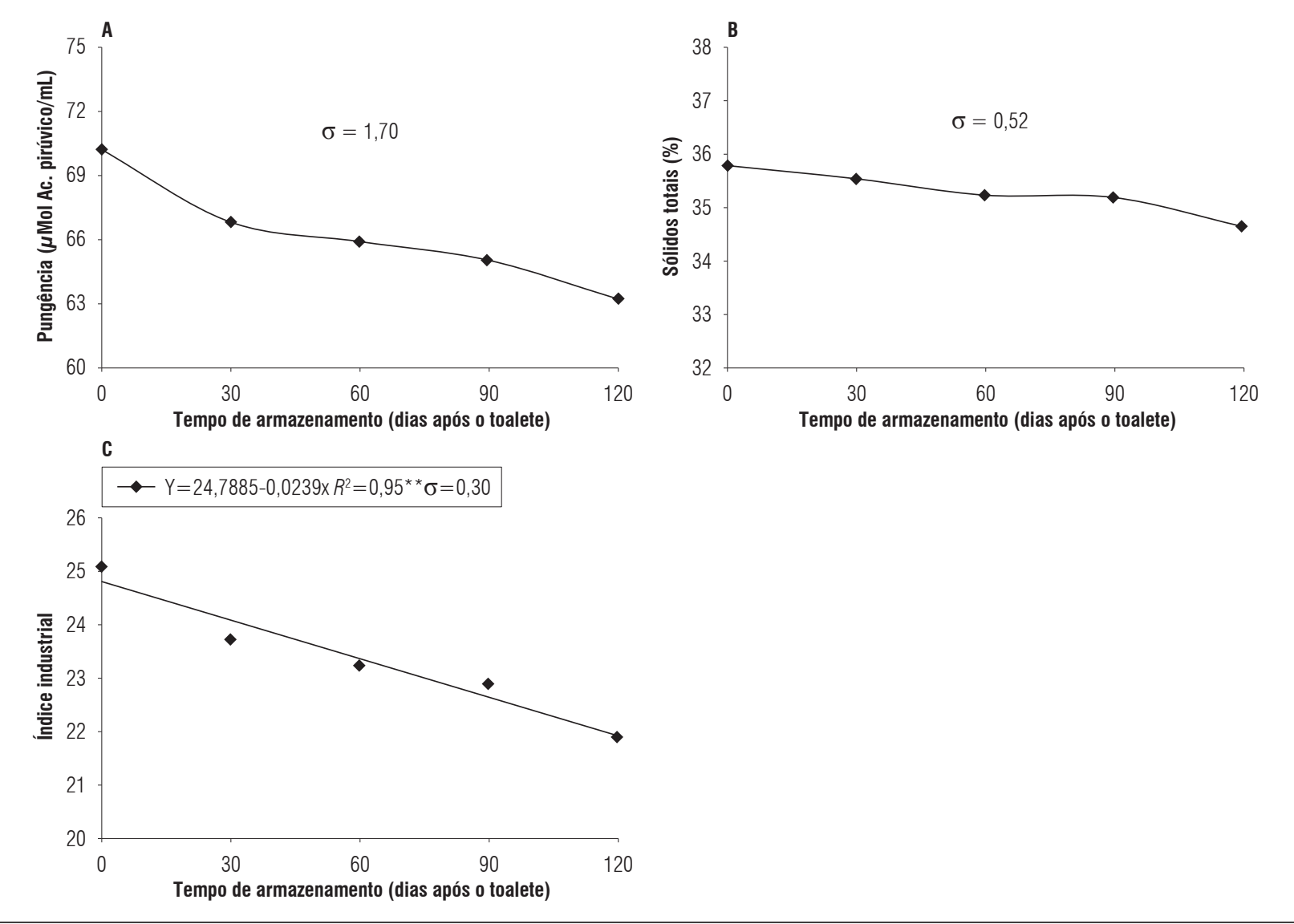

Figura 3. Pungência (A), sólidos totais (B) e índice industrial (C) de cultivares de alho armazenado [significativo ao nível de $5 \%$ $(*)$ e $1 \%(* *)$ de probabilidade]. 
isolada de açúcares ou da acidez, pois reflete o balanço entre açúcares e ácidos (Chitarra e Chitarra, 2005). Variação entre 4,42 e 5,91 na relação SS/AT foi encontrada por Lopes et al. (2016a) e valores de 3,96 e 6,16 na relação SS/AT foram encontrados por Soares (2013), avaliando diferentes cultivares de alho.

Com relação a pungência não foi observado efeito significativo dos tempos de armazenamento sobre a pungência, com média de $66,27 \mu \mathrm{mol} \mathrm{mL} \mathrm{mL}^{-1}$ de ácido pirúvico. No entanto, verificou-se tendência de redução ao longo do armazenamento (Fig. 3A), o que pode ter ocorrido devido à volatilidade do ácido pirúvico com o tempo de armazenamento e, possivelmente, o aumento do índice de chochamento também influenciou na redução da pungência, de vez que os bulbos são deteriorados e, consequentemente, ocorre a perda da qualidade. De acordo com Berno (2013), é possível que essa redução esteja relacionada ao uso de ácidos orgânicos na respiração, já que eles constituem substratos respiratórios.

Esse valor está acima do encontrado por Carvalho et al. (1991), que encontraram o valor máximo de ácido pirúvico de 48,60 $\mu \mathrm{mol} \mathrm{g}^{-1}$ aos $150 \mathrm{~d}$ de armazenamento para a cultivar Amarante na região de Lavras -MG, ao passo que Lopes et al. (2016a) observaram variações de 80,59 a 99,40 $\mu \mathrm{mol} \mathrm{mL}^{-1}$ de ácido pirúvico em Baraúna-RN e Lucena et al. (2016a) observaram valores de 80,23 a $90,45 \mu \mathrm{mol} \mathrm{mL}^{-1}$ de pungência em Baraúna-RN, e 67,32 a 76,10 $45 \mu \mathrm{mol} \mathrm{mL}^{-1}$ em Governador Dix-sept Rosado-RN.

Em relação às cultivares, não se verificou diferença entre seus níveis de pungência (Tab. 2).

Tabela 2. Relação sólidos solúveis/acidez titulável (SS/AT), pungência, sólidos totais (ST) e índice industrial (II) de cultivares de alho armazenado.

\begin{tabular}{|l|c|c|c|c|}
\hline \multicolumn{1}{|c|}{ Cultivar } & SS/AT & $\begin{array}{c}\text { Pungência } \\
\left(\mu \mathrm{mol} \mathrm{mL}^{-1}\right)\end{array}$ & $\begin{array}{c}\text { ST } \\
(\%)\end{array}$ & ॥ \\
\hline R. Pérola de Caçador & $5,78 \mathrm{~b}$ & $67,97 \mathrm{a}$ & $33,39 \mathrm{~b}$ & $22,69 \mathrm{a}$ \\
\hline BRS Hozan & $6,64 \mathrm{a}$ & $64,57 \mathrm{a}$ & $37,18 \mathrm{a}$ & $24,02 \mathrm{a}$ \\
\hline Desvio padrão & 0,14 & 2,11 & 0,43 & 0,73 \\
\hline
\end{tabular}

Médias seguidas pela mesma letra, para cada característica, não diferem entre si pelo teste t a $5 \%$ de probabilidade.

Sabe-se que o grau de pungência no alho é proporcional ao teor de ácido pirúvico formado (Vargas et al., 2010; Soares, 2013). No entanto, não se observou uma relação direta entre a pungência e a acidez titulável (AT), pois outros ácidos também compõem a AT.
Para sólidos totais (ST) dos bulbos não houve efeito significativo, com valor médio de $35,28 \%$. No entanto, assim como para a pungência, verificou-se tendência de redução de ST em função do tempo de armazenamento (Fig. 3B). Em relação às cultivares, houve efeito significativo, sendo a BRS Hozan superior à Roxo Pérola de Caçador (Tab. 2).

Apesar de a taxa de respiração do alho ser considerada muito baixa (Chitarra e Chitarra, 2005), a tendência de redução no teor de sólidos totais ocorreu devido à utilização, durante o processo respiratório, de carboidratos armazenados nos bulbilhos. Carvalho et al. (1991) também observaram redução no teor dos sólidos totais de 32,74 a $28,35 \%$ aos 0 e 120 d de armazenamento. Lopes et al. (2016a) verificaram variação no teor de sólidos totais de 31,65 a $35,28 \%$, ao passo que Lucena et al. (2016a), trabalhando com o mesmo grupo de cultivares comuns ou semi-nobre estudadas no presente trabalho, observaram valores máximos estimados de sólidos totais de 41,19\%, em Baraúna, RN e 37,23\%, em Governador Dix-sept Rosado, RN.

Observou-se comportamento linear decrescente no índice industrial com os períodos de armazenamento, com valores estimados de no máximo 24,79 e mínimo de 21,92, aos 0 e $120 \mathrm{~d}$ após o toalete, respectivamente (Fig. 3C). Não se observou diferenças entre as cultivares para índice industrial (Tab. 2).

Como houve tendência de redução no teor de sólidos totais e na pungência, com o tempo de armazenamento, também foi observada redução no índice industrial. Esta é uma característica importante quando se deseja obter alho para a desidratação, sendo essa resultante da associação entre os teores de sólidos totais e ácido pirúvico. Portanto, quanto maiores forem os teores simultaneamente de sólidos totais e de ácido pirúvico, melhor será a qualidade para a desidratação.

Carvalho et al. (1991) observaram médias de 12,02 a 12,21 aos 0 e $120 \mathrm{~d}$ de armazenamento, respectivamente. Lopes et al. (2016a) verificaram variação de 28,33 a 33,33 de índice industrial em Baraúna, $\mathrm{RN}$, ao passo que Lucena et al. (2016a) obtiveram valores de índice industrial de 27,22 a 36,67 em Baraúna, RN, e 25,15 a 28,07 em Governador Dix-sept Rosado, RN.

\section{CONCLUSÕES}

Com o tempo de armazenamento, houve aumento na perda de peso, índice de chochamento e acidez 
titulável, além de redução no $\mathrm{pH}$, relação SS/AT e índice industrial, para as duas cultivares avaliadas. O alho manteve o padrão ideal para consumo até os $120 \mathrm{~d}$ de armazenamento, para ambas as cultivares. A cultivar Roxo Pérola de Caçador teve potencial de armazenamento superior a cultivar BRS Hozan.

Conflito de interesses: o manuscrito foi preparado e revisado com a participação de todos os autores, que declaram não ter qualquer conflito de interesses que possa afetar a validade dos resultados do trabalho apresentado.

\section{REFERÊNCIAS BIBLIOGRÁFICAS}

ANAPA. 2014. Associação nacional dos produtores de alho. Nosso Alho No. 13. Brasília, Brasil.

Beckles, D.M. 2012. Factors affecting the postharvest soluble solids and sugar content of tomato (Solanum lycopersicum L) fruit. Postharvest Biol. Technol. 63(1), 129-140. Doi: 10.1016/j.postharvbio.2011.05.016

Berno, N.D. 2013. Processamento mínimo de cebola roxa: aspectos bioquímicos, fisiológicos e microbiológicos. Dissertação de mestrado. Escola Superior de Agricultura Luís de Queiroz-ESALQ, Piracicaba, Brasil.

Botrel, N. e V.R. Oliveira. 2012. Cultivares de cebola e alho para processamento. Hortic. Bras. 30(230), S8420S8434.

Carvalho, V.D., S.M. Chalfoun, C.M.P. Abreu e S.J.R. Chagas. 1991. Tempo de armazenamento na qualidade do alho cv. Amarante. Pesq. Agropec. Bras. 26(10), 1679-1684.

Chitarra, M.I.F. e A.B. Chitarra. 2005. Pós-colheita e frutos e hortaliças: fisiologia e manuseio. $2^{\mathrm{a}}$ ed. UFLA, ESAL/ FAEPE, Lavras, Brasil.

Ferreira, D.F. 2008. Sisvar: um programa para análises e ensino de estatística. Rev. Symposium 6(2), 36-41.

Honorato, A.R.F., M.Z. Negreiros, F.V. Resende, W.A.R. Lopes e A.M Soares. 2013. Avaliação de cultivares de alho na região de Mossoró. Rev. Caatinga 26(3), 80-88.

Lopes, W.A.R., M.Z. Negreiros, P.L.D. Morais, A.M. Soares, R.R.M. Lucena, O.M.P. Silva e L.C. Grangeiro. 2016a. Caracterização físico-química de bulbos de alho submetido a períodos de vernalização e épocas de plantio. Hortic. Bras. 34(2), 231-238. Doi: 10.1590/ S0102-053620160000200013
Lopes, W.A.R., M.Z. Negreiros, F.V. Resende, R.R.M. Lucena, A.M. Soares, O.M.P. Silva e J.F. Medeiros. $2016 b$. Produção de alho submetido a períodos de vernalização e épocas de plantio em região de clima semiárido. Hortic. Bras. 34(2), 249-256. Doi: 10.1590/ S0102-053620160000200016

Lucena, R.R.M., M.Z. Negreiros, P.L.D. Morais, W.A.R. Lopes e A.M. Soares. 2016a. Qualitative analysis of vernalizated semi-noble garlic cultivars in western Rio Grande do Norte state, Brazil. Rev. Caatinga 29(3), 764-773. Doi: 10.1590/1983-21252016v29n329rc

Lucena, R.R.M., M.Z. Negreiros, F.V. Resende, W.A.R. Lopes e O.M.P. Silva. 2016b. Productive performance of vernalizated semi-noble garlic cultivars in western Rio Grande do Norte State, Brazil. Rev. Caatinga 29(2), 327-337. Doi: 10.1590/1983-21252016v29n209rc

Oliveira, C.M., R.J. Souza, J.E. Yuri, J.H. Mota e G.M. Resende. 2004. Época de colheita e potencial de armazenamento em cultivares de alho. Hortic. Bras. 22(4), 804-807. Doi: 10.1590/S0102-05362004000400029

Prati, P., D.E. Foltran, C.M. Henrique e C.P.C.C. Martins. 2010. Alterações físico-químicas em pastas de alho. Rev. Iber. Tecnología Postcosecha 11(2), 191-195.

Resende, J.T.V., R.G.F. Morales, D.S. Zanin, F.V. Resende, J.T. Paula, D.M. Dias e A.G. Galvão. 2013. Caracterização morfológica, produtividade e rendimento comercial de cultivares de alho. Hortic. Bras. 31(1), 157-162. Doi: 10.1590/S0102-05362013000100025

Resende, G.M., S.J.R. Chagas e L.V. Pereira. 2003. Características produtivas e qualitativas de cultivares de alho. Hortic. Bras. 21(4), 686-689. Doi: 10.1590/ S0102-05362003000400023

Soares, A.M. 2013. Avaliação de cultivares de alho no município de Governador Dix-sept Rosado-RN. Dissertação de mestrado. Universidade Federal Rural do Semi-árido, Mossoró, Brasil.

Soares, A.M., M.Z. Negreiros, F.V. Resende, W.A.R. Lopes, J.F. Medeiros e L.C. Grangeiro. 2015. Avaliação de cultivares de alho no município de Governador Dix-sept Rosado-RN, Brasil. Rev. Agroamb. 9(4), 423-430.

Souza, R.J. e F.S. Macêdo. 2009. Cultura do alho: Tecnologias modernas de produção. Universidade Federal de Lavras, Minas Gerais, Brasil.

Vargas, V.C.S., R.E. González, M.M. Sance, J.L. Burba e A.B. Camargo. 2010. Efecto de la interacción genotipo-ambiente sobre la expresión del contenido de allicina y ácido pirúvico en ajo (Allium sativum L.). Rev. FCA UNCuyo 42(2), 15-22. 